\title{
O IMBRICAMENTO DE FLASHBACKS NA ADAPTAÇÃO DO ROMANCE OMARAVILHOSO MÁGICO DE OZ PARA HQ
}

\author{
FLASHBACK EMBEDMENT IN THE \\ WONDERFUL WIARD OF OZADAPTATION TO \\ COMICS
}

\author{
LA IMBRICACIÓN DE FLASHBACKS EN LA \\ ADAPTACIÓN DE LA NOVELA EL \\ MARAVILLOSO MAGO DE OZ PARA CÓMICS
}

\footnotetext{
${ }^{1}$ É mestra e doutoranda em Estudos Linguísticos e Literários em Inglês pela Universidade de São Paulo, bolsista processo no 2017/02150-0, Fundação de Amparo à Pesquisa do Estado de São Paulo (FAPESP).
} 
RESUMO: O Maravilhoso Mágico de $O z$, de L. Frank Baum, recebeu diversas adaptações, sendo a maioria delas para sistemas semióticos sincréticos, como o cinema e os quadrinhos, cuja análise permite uma exploraçáo dos recursos utilizados tanto pela obra original quanto pela adaptada. Este trabalho estuda como as memórias de algumas das personagens principais são apresentadas ao leitor tanto na obra original quanto na recente adaptaçáo homônima para os quadrinhos.

ABSTRACT: The Wonderful Wizard of $O z$, by L. Frank Baum, has had several intersemiotic translations, most of which to syncretic semiotic systems, like movies, and comic books, whose analysis allows us to better explore the resources used both by the original piece and the adapted one. This paper aims to compare how some leading figures' memories are presented to the reader both in the original piece and the its comic book intersemiotic translation.

RESUMEN: El Maravilloso Mago de Oz, de L. Frank Baum, recibió varias adaptaciones, siendo la mayoría de ellas para sistemas semióticos sincréticos, como el cine y los cómics, cuyo análisis permite una explotación de los recursos utilizados tanto en la obra original como en la adaptada. Este trabajo estudia cómo las memorias de algunos de los personajes principales son presentadas al lector en la obra original y en la reciente adaptación homónima para los cómics.

PALAVRAS-CHAVE: História em Quadrinhos; Imbricamento; O Mágico de Oz; Semiótica

KEY-WORDS: Comic Books; Embedding; The Wizard of Oz; Semiotics

PALABRAS CLAVE: Cómics; Imbricación; El Maravilloso Mago de Oz; Semiótica.

Uma das preocupaçóes verificadas ao longo do desenvolvimento da teoria semiótica foi a possibilidade de analisar textos que se valessem de várias linguagens em sua forma de expressão, chamados enunciados "sincréticos". Antonio Vicente Pietroforte, que dedicou boa parte de seus estudos para esse tipo de objeto, explica:

Para a semiótica, há uma forma no conteúdo - ou seja, uma semântica - que realiza o sentido, e uma forma na expressão, que o manifesta. Nessa relação entre a forma do conteúdo e a forma da expressão, o sentido é construído nos textos. Partindo da hipótese de trabalho temporária de que é possível manifestar conteúdos semelhantes em planos de expressão distintos, nada impede que se separe plano de conteúdo para, em um primeiro momento, descrever o percurso gerativo do sentido apenas no plano de conteúdo. Essa hipótese de trabalho se justifica porque o mesmo conteúdo pode ser manifestado em planos de expressão fonológicos, plásticos, musicais ou sincréticos, sem danos significativos à sua forma semântica. É evidente que a expressão modifica o conteúdo, visto que uma HQ não é a mesma coisa que um poema, no entanto, em nome da 
aspiração científica, deve-se isolar as variaçóes da expressão e procurar aquilo que é sistemático na formação do sentido no plano de conteúdo (2009, p. 11, grifos nossos).

O presente trabalho propõe uma análise como a descrita por Pietroforte, a fim de estudar uma HQ - objeto sincrético, que une, em seu plano de expressão, as linguagens verbal e plástica, ditas "verbo-visuais" (DISCINI, 2009, p. 188) - em perspectiva comparatista com a obra original. A HQ em questão é The Wonderful Wizard of $\mathrm{Oz}$ [O Maravilhoso Mágico de Oz], de Eric Shanower e Skottie Young, publicada pela Marvel, adaptada da obra homônima de autoria de L. Frank Baum, a partir da qual discorreremos sobre a manifestação do passado ao programa narrativo de base, em contraste com o presente, que é a linha temporal principal, através do imbricamento de flashbacks enquanto programas narrativos de uso.

É importante observar, previamente, que uma adaptação intersemiótica de uma obra literária para uma HQ não contém certas particularidades de uma obra originalmente criada como HQ, como exemplifica Norma Discini abaixo:

[...] como procedimento de fusão entre linguagens diferentes, o enunciado sincrético não apresenta marcas indicativas daquilo que veio antes ou depois no processo de sua construção, o visual ou o verbal. Esse procedimento faz parte da própria estratégia de sincretização (2009, p. 190).

Se, por um lado, a adaptação em análise não apresenta "marcas indicativas daquilo que veio antes no processo de sua construção", por outro, por se tratar justamente de uma adaptação, poder-se-ia considerar de antemáo que o verbal precedeu o visual, visto que boa parte das falas dos “atores enunciados no texto" (Cf. DISCINI, 2009, p. 44) é idêntica às da obra original, bem como as ocasionais narrações. Apesar disso, é possível considerar a questão da tradução intersemiótica por outro ângulo, sem trabalhar a evidente intertextualidade: apesar de a HQ basear-se em texto já existente, ocorre nela uma consecução do verbal ao visual, visto que, por ter outro plano de expressão, sincrético, o plano do conteúdo acaba por lhe ser próprio e outro (embora guarde relação fundamental com o romance que a originou).

Apontamos esse fato para frisar que nos utilizamos de teorias relativas à análise de HQs, uma vez que estas constituem um enunciado sincrético, independentemente de sua origem criativa, e é indiscutível que a obra de Eric Shanower e Skottie Young se trata de uma HQ, por 
apresentar todas as características pré-estabelecidas desse gênero, segundo podemos apreender no trecho abaixo de Norma Discini:

\begin{abstract}
Voltemos ao esquema fundante do gênero HQ. Acrescentamos que traz consequências para o estilo do gênero uma composição que supóe, no plano da expressão, recursos como: cenas encerradas em quadriláteros; falas contidas por balóes; balóes arrematados por linhas retas, sinuosas ou onduladas, estas duas últimas que costumam reconstruir sensorialmente o efeito de flash-back ou a anterioridade temporal do narrado [...] (2009, p. 193).
\end{abstract}

As características supracitadas, incontestavelmente, compóem tanto $\mathrm{HQs}$ de roteiro original como adaptações intersemióticas, portanto, tornam-se indispensáveis à presente análise. Há que se considerar ainda, os seguintes recursos presentes no gênero de HQ:

Traz consequências para o estilo do gênero a textualização manifestada sincreticamente. Também traz consequências o fato de que, do plano do conteúdo, possam emergir teatralmente atores que dialogam num tempo presente, passado ou futuro, todos em relaçáo concomitante ao ato de enunciar, na delegação de vozes feita pelo narrador. Nos textos de HQ, a predominância desse fato da sintaxe discursiva orienta o estilo de gênero. Se pensarmos na fala dramatizada como traço distintivo do conteúdo dos textos concernentes ao gênero, veremos que a enunciação debreada em segundo grau nos faz deparar com um narrador que raramente se assume como protagonista da própria história. Esse narrador costuma aparecer em terceira pessoa, restrito visualmente a algum vão entre os quadros, ou no topo deles, ou em tira lateral a eles. $\mathrm{O}$ deslocamento da voz do narrador para as margens, como solução visual, reforça a debreagem de segundo grau como elemento central do esquema composicional do gênero. Importa o relato da fala dos interlocutores feito por meio do discurso direto. Daí decorrem as falas encerradas nos balôes (DISCINI in OLIVEIRA; TEIXEIRA, 2009, pp. 193-4).

Todas essas características aparecem bem marcadas na adaptação The Wonderful Wizard of $\mathrm{Oz}$ e algumas delas são fundamentais para o recorte deste estudo: a forma como ocorre o imbricamento de programas de uso por meio de flashbacks na HQ.

Tanto no romance original quanto na HQ adaptada, o programa narrativo de base e seus programas narrativos subordinados tratam da busca dos sujeitos Dorothy (que, após ter sido levada, dentro de sua casa, por um ciclone até a terra mágica de $\mathrm{Oz}$, procura uma forma de retornar ao Kansas, seu lar), Espantalho (que busca um cérebro, figurativizando o valor “inteligência”), Homem de Lata (que busca um coração, figurativizando o valor "sentimentos”) e 
Leão Covarde (que busca o valor "coragem"), com constantes fazeres emissivos e remissivos, que determinam um formato de narrativa episódica através do surgimento de diversos obstáculos, responsáveis pela remissividade e consequente desaceleração e fechamento do espaço, alternado com a superação de ditos obstáculos, trazendo emissividade e consequente aceleração e abertura do espaço.

Essa busca será percebida com certo humor pelo enunciatário-leitor, pois, como se percebe ao longo do texto, os sujeitos já estão em conjunção com seus respectivos objetos de valor, apenas creem não estar. Pietroforte resume bem a tensão que permeia o programa narrativo de base no trecho abaixo:

Até a chegada de Dorothy e seus amigos na cidade de Oz, há tensôes constantes entre o ser e o parecer das coisas. O Espantalho, que se julga tolo, é o mais sagaz; o Homem de Lata, que pensa ter perdido suas emoçóes, é o mais sentimental; e o Leão, que se considera covarde, age como verdadeiro herói. Os três vão a $\mathrm{Oz}$ para pedir ao mágico, respectivamente, um cérebro, um coração e muita coragem. Dorothy, por sua vez, quer voltar para casa, sem saber que traz consigo, o tempo todo, os sapatos encantados capazes de realizar o seu desejo (2008, p. 50).

Apesar da tensão provocada pelo conflito e pelas repetidas sequências remissivas, ao final há uma tendência ao relaxamento, com a conjunção dos sujeitos com seu objeto de valor ou, como se explicita ao enunciatário-leitor, com a eliminação da tensão entre ser e parecer apontada acima por Pietroforte, no momento em que os sujeitos começam a crer ser aquilo que queriam ser.

A partir desse programa narrativo de base, passemos ao imbricamento dos flashbacks, em que cinco programas de uso, em forma de micronarrativas, são inseridos em meio à narrativa principal, três das quais têm por finalidade explicar como os sujeitos Espantalho, Homem de Lata e Leão Covarde passaram a ter seus respectivos objetos de valor - inteligência, sentimentos e coragem - , dando origem a suas buscas.

Primeiramente, vejamos como se dá a construção do sentido na $\mathrm{HQ}$ :

A HQ é estabilizada por meio de mecanismos próprios à sintaxe e à semântica discursivas: a história é narrada predominantemente a partir do espaço de alhures; figuras visuais garantem o detalhamento topológico, a que se emparelha 
o protocolo implícito da introdução do narrado: "Era uma vez..." (DISCINI in Oliveira; Teixeira, 2009, p. 197).

O "detalhamento topológico" a que se refere a primeira citação é parte da linguagem plástica, para cuja análise contribui o semissimbolismo, segundo Pietroforte:

Para os estudos do semi-simbolismo [sic] em outras semióticas [além da verbal], basta determinar aquelas categorias que são pertinentes à forma do plano de expressáo realizado e examinar os modos de semi-simbolização possíveis entre elas e as categorias semânticas do plano de conteúdo (2009, p. 19).

Em semióticas plásticas, há três tipos das categorias de expressão, como mencionado acima por Pietroforte: as cromáticas, que se referem à cor, as eidéticas, que dizem respeito à forma, e as topológicas, que tratam da distribuição textual das cores e formas.

Entretanto, uma HQ é uma construção sincrética, e não apenas plástica, de forma que as categorias de expressão cromáticas, eidéticas e topológicas fazem parte de um conjunto maior de categorias de análise. Norma Discini aponta:

$\mathrm{Na} \mathrm{HQ}$, temos um referente, cuja veridicção está relacionada aos mecanismos de construção do sentido segundo o sincretismo verbovisual. Se um romance [...] é retomado por uma HQ [...], ficam demonstrados procedimentos diferentes de ancoragem actorial, espacial e temporal, em função da manifestação sincrética na $\mathrm{HQ}$, bem como em função das diferentes esferas de comunicação pressupostas" (DISCINI in Oliveira; Teixeira, 2009, p. 186).

Como é possível apreender da citação acima, se apenas o plano de conteúdo guarda semelhanças entre as adaptaçóes, como já afirmado por Pietroforte, há que se considerar os diferentes procedimentos de ancoragem que ocorrem na manifestação sincrética para efeitos de análise.

$\mathrm{Na}$ HQ The Wonderful Wizard of $\mathrm{Oz}$, notam-se diversos esquemas de cor na composição das cenas que dão forma à narrativa. Em uma análise geral, tais esquemas correspondem à oposiçấo entre o Kansas (cores escuras, insaturadas, com predominância de cinza e marrom) e $\mathrm{Oz}$ (cores mais vivas e diversificadas), e entre os períodos do dia na Terra de Oz (cores claras com predomínio de azul e verde nos ambientes externos durante a manhã e o começo da tarde, e marrom claro e amarelo, que referencializam a luz solar nos raros ambientes internos; tons 
escuros, porém vibrantes, com predominância de azul, durante a noite; tons insaturados, puxados para o pastel e com predomínio de tons alaranjados durante o fim da tarde ou crepúsculo).

Esses recursos cromáticos por si só transmitem, na HQ, a passagem do tempo, que precisa ser descrita verbalmente na obra literária.

Como o espaço é majoritariamente aberto, sobretudo durante o percurso de Dorothy a caminho da Cidade das Esmeraldas, temos predominância de quadros em plano aberto (cf. Figura 1, em que a vemos minúscula no quadrante inferior esquerdo), alguns ocupando o espaço equivalente a dois, três e até a seis quadros do tamanho padrão da HQ. Assim, no plano da expressão, a aceleração do sujeito se manifesta e a abertura do espaço se dá, não apenas pelo plano, como pela angulação do desenho, pelo tamanho e forma dos quadros.

Figura 1: apresentação de Dorothy e o Kansas

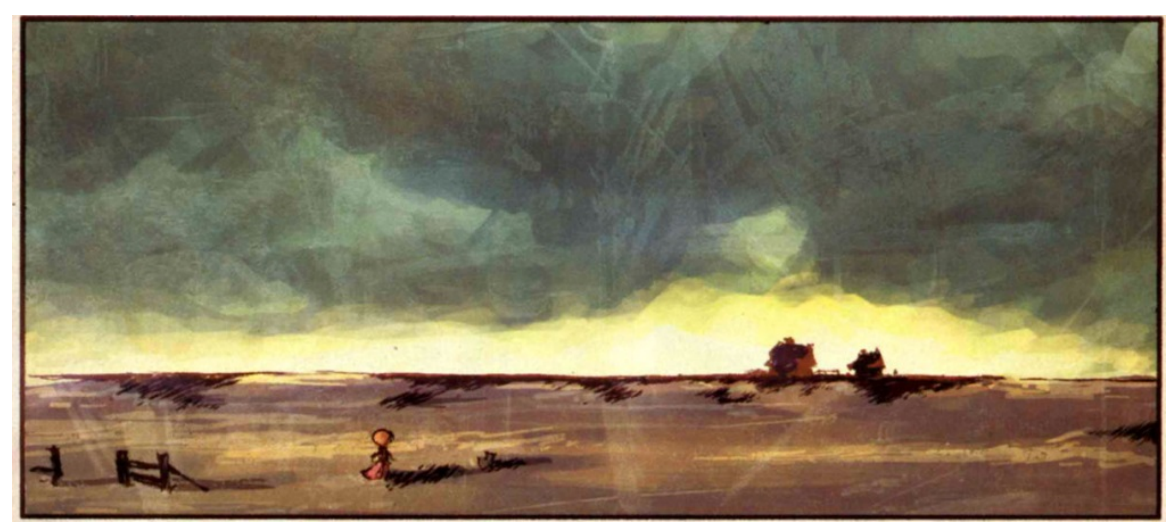

Extraído de SHANOWER, 2014, p. 1.

Durante a jornada, Dorothy pausa para descansar, o que pode ser considerado um antissujeito átono (TATIT, 2010, p. 53), uma vez que não corresponde a um fazer remissivo do sujeito, posto que não prejudica verdadeiramente o programa de base, mas é quando começa a conhecer os amigos que a acompanharão durante a aventura, tendo buscas próprias, mas procurando seguir o mesmo caminho.

O primeiro encontro é com o Espantalho, momento em que ocorre a desaceleração de Dorothy e o consequente fechamento do espaço para um milharal. Naquele instante, talvez, o Espantalho configure momentaneamente um antissujeito átono da protagonista, uma vez que é o causador de seu fazer remissivo: ele se encontra preso no alto de uma haste de madeira, chamando a atenção da menina e provocando sua parada. Após breve interaçáo, Dorothy o liberta, 
tornando-se, nesta ação, sua destinadora por ter lhe doado a competência de poder caminhar livremente (SHANOWER, 2014, p. 26).

Juntos continuam a jornada, voltando à aceleração emissiva e recobrando a abertura do espaço. Em dada ocasião, ocorre o primeiro imbricamento de flashback (idem, pp. 30-2, cf. Figura 2): o Espantalho começa a contar a Dorothy como foi criado e por que busca o objeto de valor inteligência.

Figura 2: flashback do Espantalho

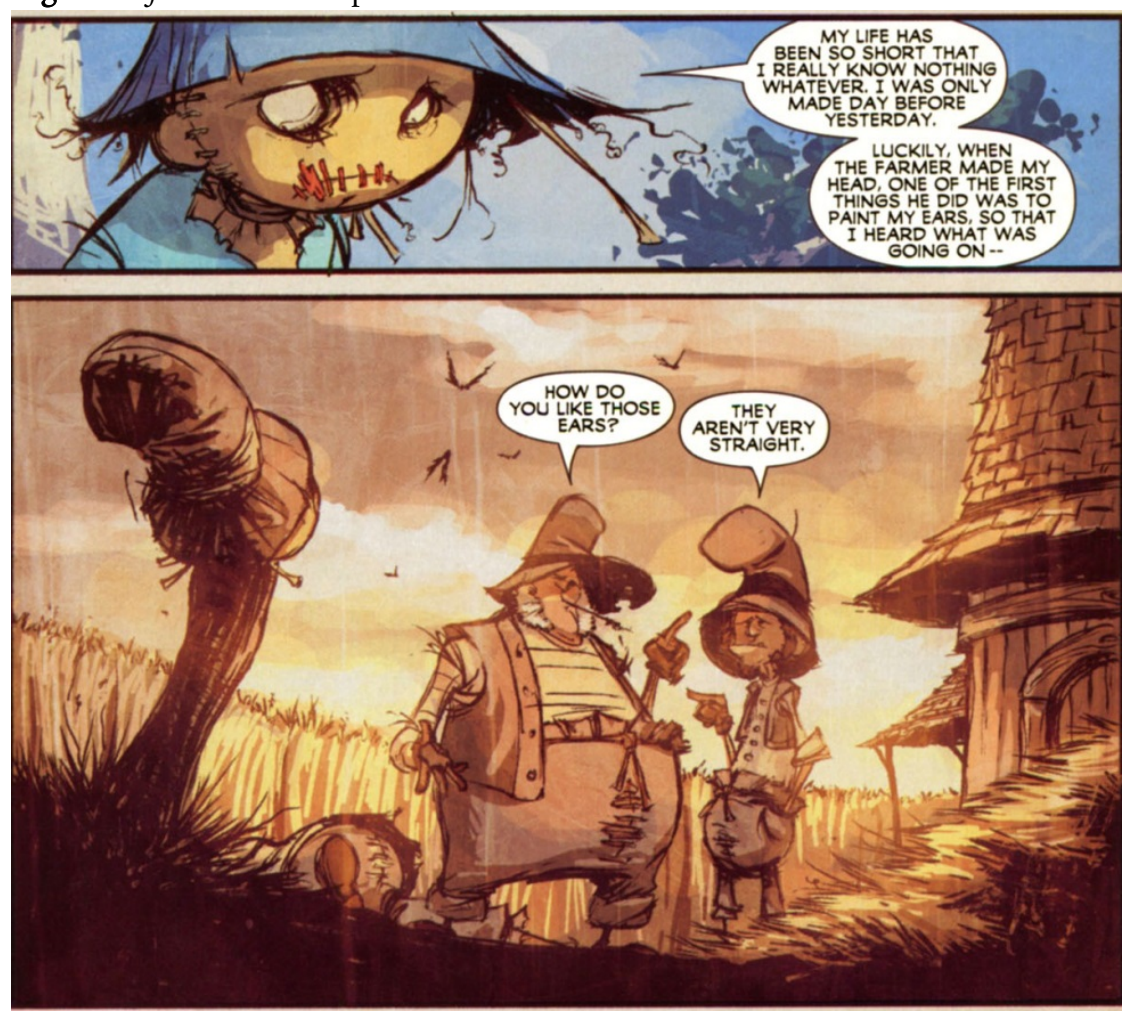

Extraído de SHANOWER, 2014, p. 30.

Conforme observamos a partir da Figura 2, até entáo, as cores das cenas contidas nos quadros seguem o esquema relativo à manhã, como descrito anteriormente. A cena do quadro que antecede o imbricamento (SHANOWER, 2014, p. 30) é a que vemos no quadro superior. É possível constatar que a fala do sujeito ${ }^{2}$ está contida em dois balóes de traço contínuo e contorno oval, emendados verticalmente com leve desalinho à direita.

O quadro seguinte traz um esquema monocromático, com sobretons insaturados entre o marrom e o laranja. A partir desse quadro e pelos próximos, a cena segue esse esquema de cores, o

\footnotetext{
${ }^{2}$ Utilizamos uma tradução do romance, visto que a fala do sujeito na HQ reproduz à risca a da obra original, com alguns cortes: "Minha vida foi tão curta que não sei nada de qualquer coisa. Eu só fui feito anteontem. [...] Felizmente, quando o fazendeiro fez a minha cabeça, uma das primeiras coisas que ele fez foi pintar minhas orelhas, de modo que eu ouvi o que se passava [...]" (BAUM, 2014, pp. 37-8).
} 
espaço é outro e o tempo é anterior ao do resto da narrativa, com a presença de dois sujeitos que não haviam aparecido antes. Quando o trecho termina (idem, p. 32), o flashback se encerra.

Durante essa micronarrativa, que é um programa de uso, o Espantalho assume o papel de narrador, tornando-se um narrador temporário, e suas falas passam a vir encerradas em caixas brancas ou soltas em um canto do quadro. Diferentemente do que ocorre com o narrador em terceira pessoa, as falas do Espantalho aparecem entre aspas, demonstrando que aquela posição é uma concessão e será breve. De fato, isso só dura até o fim do flashback.

Os novos sujeitos, os fazendeiros que fizeram o Espantalho e o corvo velho dos últimos três quadros da narrativa imbricada, recebem falas em balóes, características do discurso direto em HQs, como já observado (vide Figura 3 abaixo).

Sabemos tratar-se de outro espaço porque o vemos retratado na cena, e a anterioridade do tempo narrado fica explicitada pelo contexto e pelas falas do narrador-Espantalho.

A fala do Espantalho que antecede o flashback vem seguida de duplo hífen (“--”) o que indica interrupção do discurso. O quadro seguinte, em que se inicia o flashback, já traz o discurso direto dos sujeitos fazendeiros, que pertencem àquele espaço e tempo diversos, conforme a Figura 2.

No romance, não ocorre interrupção da fala do Espantalho. O discurso prossegue: "Havia outro Munchkin com ele, e a primeira coisa que ouvi foi o fazendeiro dizendo: O que acha dessas orelhas?" (BAUM, 2014, p. 38). Assim, toda a narraçáo que explica como surgiu o Espantalho e a origem de seu querer saber, que é seu objeto de valor, se dá dentro das falas do sujeito.

Nota-se que, na HQ, há maior ênfase na performance dos atores durante o flashback. As narraçóes do Espantalho suprem a eventual incapacidade de os quadros retratarem movimentos bruscos e as paixóes experimentadas pelo sujeito naquele tempo dado. $\mathrm{Na}$ obra literária, misturam-se a performance dos atores de outrora, os pensamentos do Espantalho, e o discurso dele e a reprodução das falas dos fazendeiros dentro do próprio discurso direto do sujeito, configurando uma debreagem de terceiro grau (GREIMAS; COURTÉS, 2013, p. 112). 
Figura 3: flashbacks do Espantalho
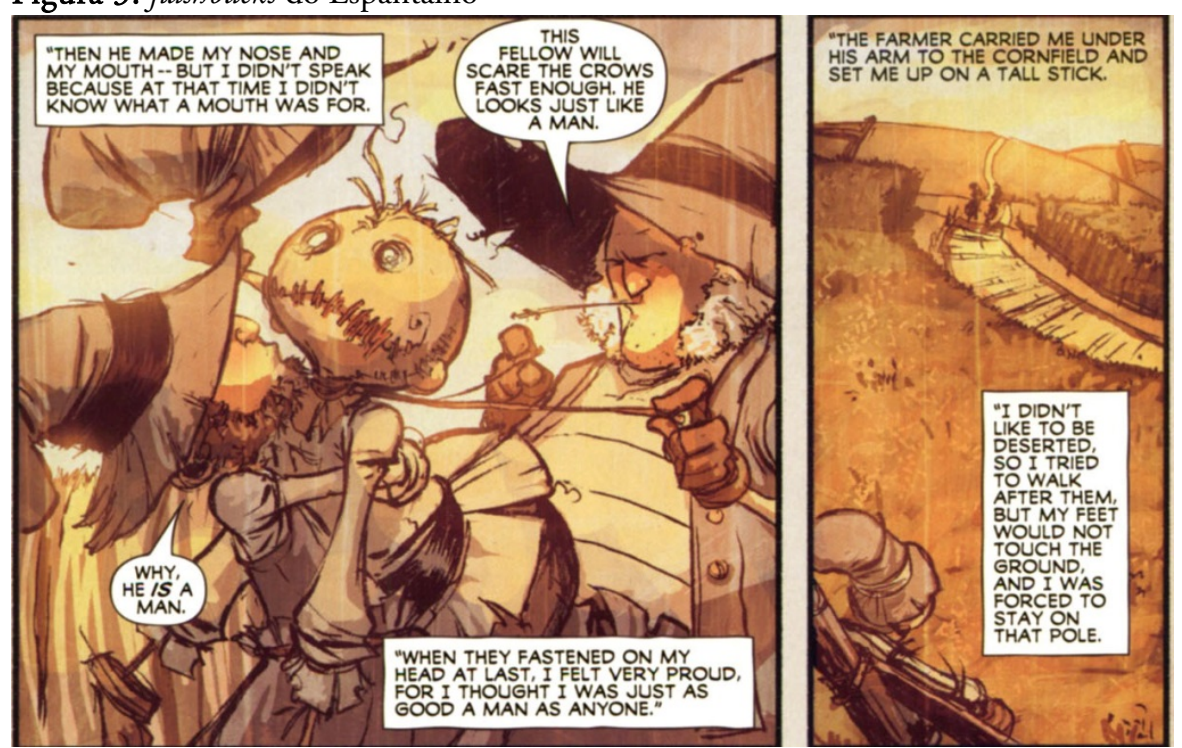

Extraído de SHANOWER, 2014, p. 31.

A diferença entre o romance e a HQ é, nesse caso, bastante pronunciada, pois, no primeiro, ocorre uma continuidade narrativa e o relato do Espantalho acontece num contexto de diálogo com Dorothy, enquanto na $\mathrm{HQ}$, embora tal fato esteja implícito, ocorre um imbricamento: há uma interrupção no programa narrativo que vinha sendo apresentado até então e a inserção de outra narrativa, dando origem a uma aparente descontinuidade, que só não se completa porque a fala interrompida é retomada na narração durante o flashback.

Um processo semelhante ocorre quando o sujeito Homem de Lata conhece Dorothy e o Espantalho e resolve contar sua história. Há, da mesma maneira, alteração do esquema cromático, precedida de um quadro em close - exatamente como ocorre no flashback anterior -, com o sujeito alinhado à esquerda do quadro estreito e comprido na horizontal (conforme a Figura 4, a seguir). 
Figura 4: flashbacks do Homem de Lata
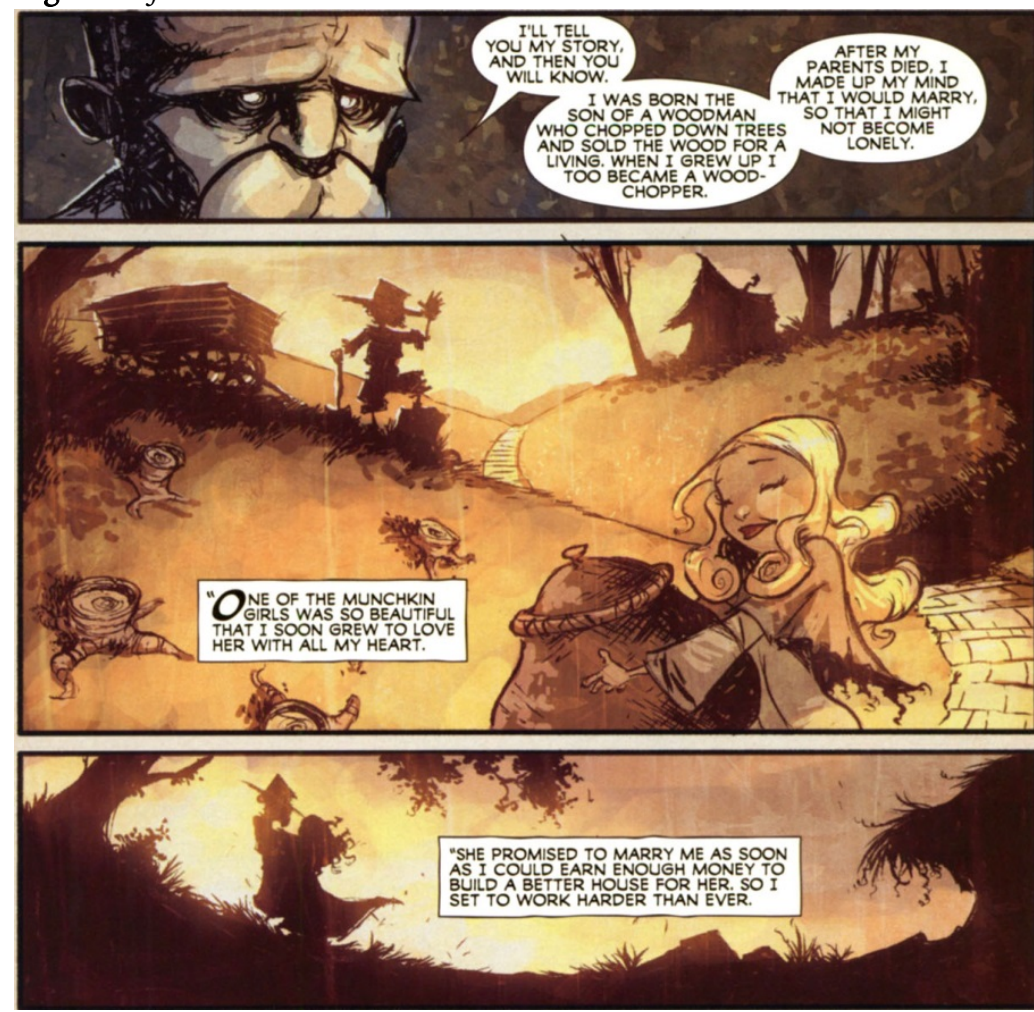

Extraído de SHANOWER, 2014, p. 39.

Após o quadro que traz essa fala, ocorre a mudança do esquema cromático que caracteriza o início do flashback. Diferentemente do que ocorreu no flashback do Espantalho, não há interrupçáo da fala do Homem de Lata no quadro anterior e os novos atores apresentados na narrativa imbricada não possuem falas. De forma semelhante ao flashback do Espantalho, o Homem de Lata torna-se o narrador temporário deste programa de uso e suas falas também aparecem dentro de quadros brancos e entre aspas.

Há três atores apresentados nesse flashback: a moça com quem o Homem de Lata pretendia se casar, que tem o papel actancial de objeto valor; uma bruxa, o antissujeito; e um ferreiro que, aos poucos, constrói o corpo de estanho do sujeito, permitindo que ele sobreviva às repetidas perdas de seus membros, assumindo o papel de destinador.

Depois que a transformação do Homem de Lata se completa, há uma pausa no flashback, seguindo-se um quadro intercalado, com o esquema cromático do programa narrativo de base associado à noite, em que figuram os três sujeitos em plano distante, com silhuetas recortadas contra o cenário, e dois balóes de fala do Homem de Lata concluindo sobre sua infelicidade pela disjunção com o objeto de valor. Seguem-se dois quadros verticais de flashback, em que as falas do 
Homem de Lata voltam à narraçáo, e ele explica como tem sido sua vida desde então, encerrando o imbricamento com a asserção da busca por seu novo objeto de valor (cf. Figura 5) - o poder sentir, figurativizado pelo coração.

Figura 5: flashbacks do Homem de Lata
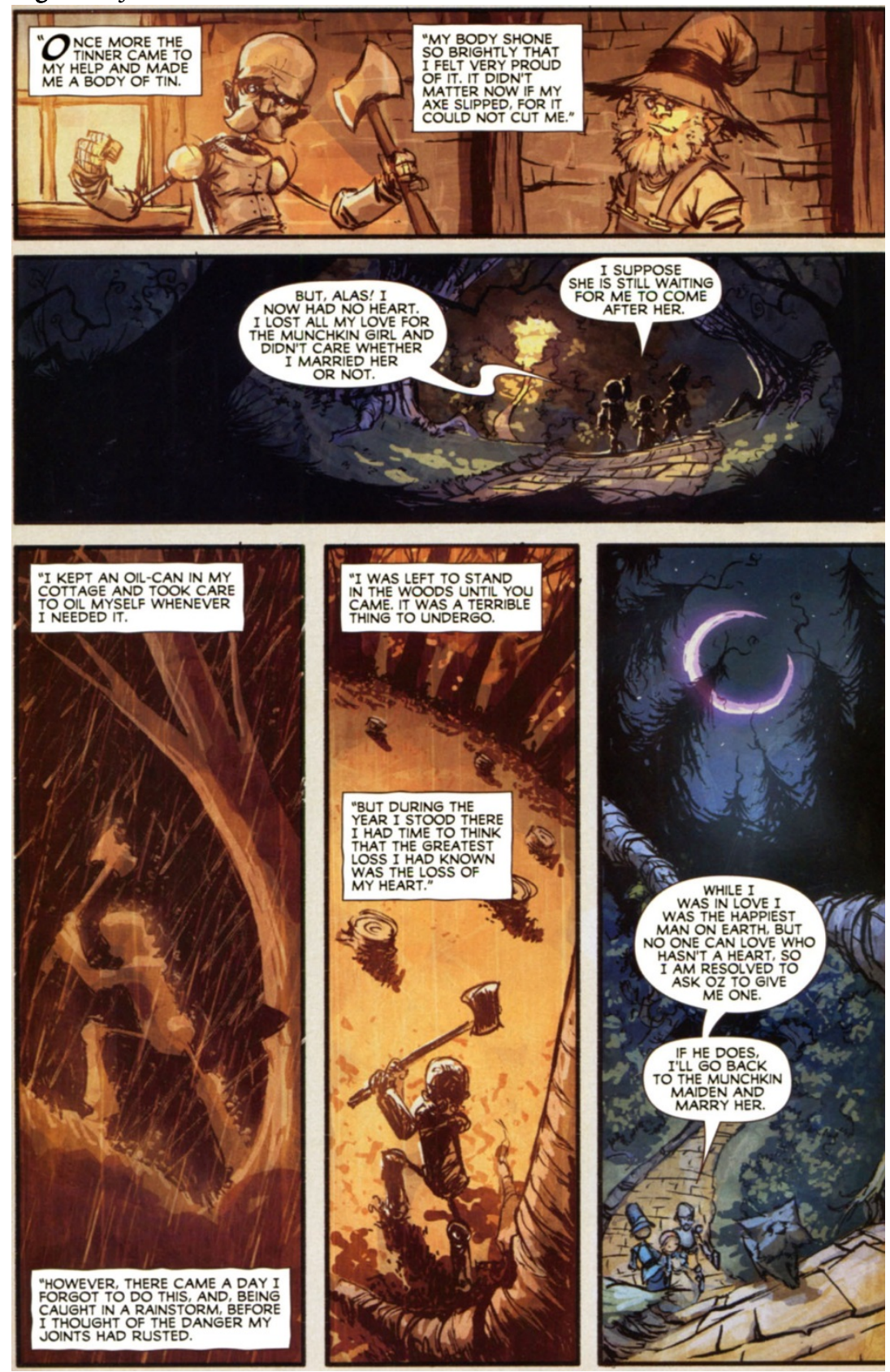

Extraído de SHANOWER, 2014, p. 41.

Nesse caso, a diferença entre o romance e a HQ é consideravelmente menor. $\mathrm{Na} H Q$, a descontinuidade narrativa causada pelo imbricamento é antes de tudo visual. Os quadros em flashback ilustram os acontecimentos narrados, mas a ausência de falas dos novos atores mantém 
uma continuidade da fala do Homem de Lata, mudando apenas seu caráter eidético: na linha temporal principal, balóes de fala; no flashback, quadros de narração. No romance, há uma pausa entre a apresentação do relato e o relato propriamente dito, além de não ocorrer no mesmo momento da passagem para o flashback na HQ, mas antes, conforme o trecho a seguir:

\footnotetext{
- Vou contar minha história, e então vocês vão saber.

Enquanto andavam pela floresta, o Homem de Lata contou a seguinte história:

Eu nasci filho [...] (BAUM, 2014, p. 46).
}

$\mathrm{Na} \mathrm{HQ}$, a pausa entre "vão saber" e "eu nasci" é dada pela troca de um baláo para o seguinte. No romance, há a inserção de um trecho do narrador, que é completamente desnecessário na HQ, pois o enunciatário vê tal ação na linguagem plástica. O flashback inicia-se depois que o Homem de Lata anuncia que tinha intenção de casar-se, já apresentando visualmente a moça que é objeto de valor do sujeito.

Já no caso do Leão Covarde, não há qualquer sinal de narrativa imbricada ou indício de narração estendida no romance; toda a razão da busca por seu objeto valor é dada em uma fala, durante um diálogo com os demais sujeitos.

$\mathrm{Na} \mathrm{HQ}$, há um flashback, introduzido por breve fala de apresentação do Leão, em close num quadro da altura padrão, e dois terços da largura da página (SHANOWER; YOUNG, 2014, p. 46), em balão duplo (dois balóes ovais emendados, conforme a figura 6). É interessante observar que tal preâmbulo é dado no final da página e o imbricamento do programa de uso inicia-se no topo de nova página.

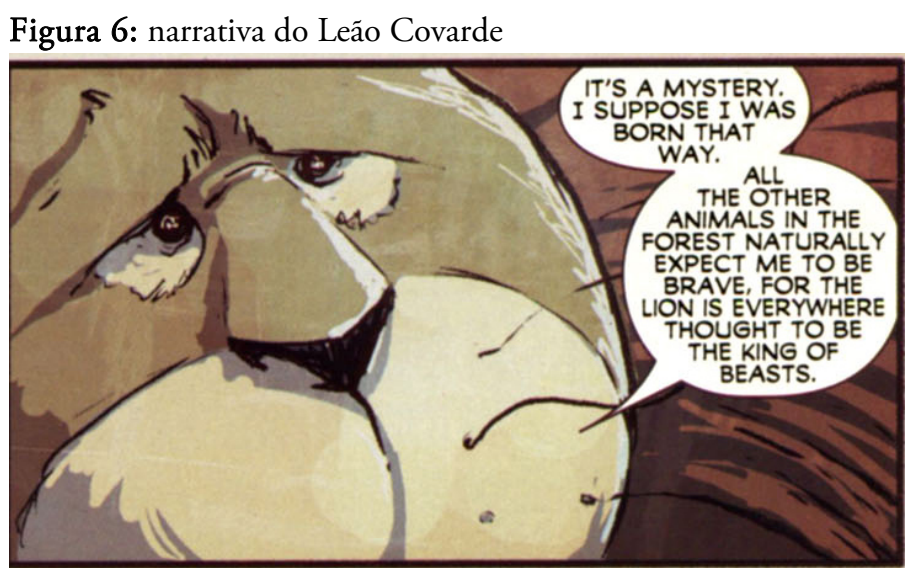

Extraído de SHANOWER, 2014, p. 46. 
A seguir (idem, p. 47), aparece o esquema cromático de flashback, narrado em quatro quadros, com o Leão alinhado à esquerda em close em todos eles e a silhueta recortada de animais variados, ao fundo, conforme vemos abaixo, na figura 7.

Figura 7: flashbacks do Leão Covarde
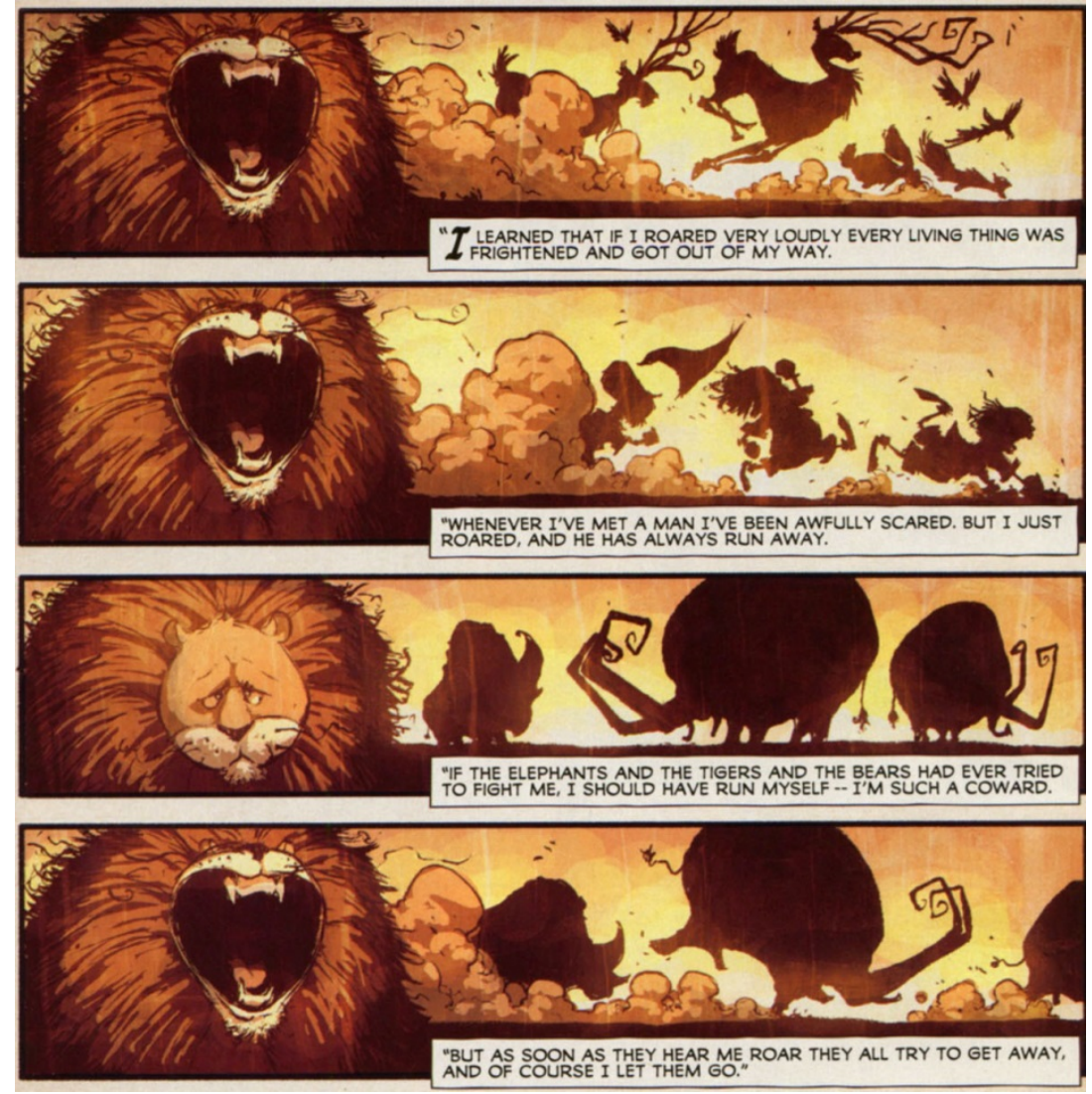

Extraído de SHANOWER, 2014, p. 47.

Como se pode observar, em todos eles, a fala em discurso direto assume a posição de narração, como no flashback do Homem de Lata, num quadro branco com duas linhas escritas na parte inferior da cena, alinhados à direita. No terceiro quadro, o Leão traz uma expressão triste que condiz com a última frase da narração: "I'm such a coward"3 (idem, p. 47). Nesse flashback, o enfoque não recai sobre a performance, mas sobre uma paixão: a frustração. O Leão sabe que não deve ser covarde, mas é, ou, antes, crê ser.

O flashback do Leão tem a mesma função dos outros dois: surgir em momentos da história quando os sujeitos ora estáo em trânsito, ora em descanso, e trazer explicaçóes narrativas que

\footnotetext{
3 "Eu sou tão covarde" (traduçâo nossa).
} 
poderiam, de outro modo, tornar a leitura da $\mathrm{HQ}$, tradicionalmente dinâmica, lenta, como observou Norma Discini no texto citado:

Ao constituir o programa narrativo privilegiado pelo discurso da novela gráfica, a performance expande o efeito de movimento na simulação da ocorrência dos fatos. $\mathrm{Na}$ textualizaçáo, verificamos o privilégio dessa fase da narrativa, na longa extensão da sequência de quadros de variados tamanhos e tipos de cercadura, dedicados à expressão das açôes em confronto. Tais narrativas narram, com apoio na saturação figurativa verbovisual, a ação do sujeito (DISCINI in OLIVEIRA; TEIXEIRA, 2009, p. 190).

O recurso de imbricamento de flashbacks parece ter permitido à HQ manter essa dinamicidade pela ênfase na performance. Tal recurso poderia, talvez, ser utilizado no romance com sucesso, uma vez que a linguagem verbal permite tipos diversos de experimentação. No entanto, considerando as características particulares de enunciados sincréticos e, em especial, as da HQ, torna-se possível reconhecer que o imbricamento de flashbacks ganha possibilidades múltiplas pela sincretização das linguagens verbal e plástica e faz cumprir seu papel na narrativa. 


\section{REFERÊNCIAS}

BAUM, L. Frank. O Maravilhoso Mágico de Oz. Trad. Carol Chiovatto. Rio de Janeiro: Vermelho Marinho, 2014.

BAUM, L. Frank. The Wonderful Wizard of Oz. Indianapolis: The Bobbs-Merrill Company, 1903.

DISCINI, Norma. "História em Quadrinhos: Um Enunciado Sincrético" in OLIVEIRA, Ana Claudia de; TEIXEIRA, Lucia (orgs.). Linguagens na Comunicaçâo -Desenvolvimentos de semiótica sincrética. São Paulo: Estação das Letras e Cores, 2009.

. O Estilo nos Textos. 2a Ed. São Paulo: Contexto, 2009.

GREIMAS, A. J.; COURTÉS, J. Dicionário de Semiótica. Vários tradutores. 2a Ed. São Paulo: Contexto, 2013.

PIETROFORTE, Antonio Vicente; GÊ, Luiz. Análise Textual da História em Quadrinhos - Uma abordagem semiótica da obra de Luiz Gê. São Paulo: Annablume, 2009.

PIETROFORTE, Antonio Vicente. Tópicos de Semiótica - Modelos Teóricos e Aplicaçôes. São Paulo: Annablume, 2008.

SHANOWER, Eric; YOUNG, Skottie. The Wonderful Wizard of Oz. 2a Ed. Nova York: Marvel, 2014.

TATIT, Luiz. Semiótica à Luz de Guimarães Rosa. Cotia, SP: Ateliê, 2010. 